\title{
Optimization of Performance Parameters and Mechanism of Bionic Texture on Friction Surface
}

\author{
Qimin Hou, Xuefeng Yang *, Jian Cheng, Shouren Wang, Derong Duan, Jupeng Xiao and \\ Wanyang Li@
}

College of Mechanical Engineering, University of Jinan, Jinan 250022, Shandong, China; houqimin0313@163.com (Q.H.); chengjian@hbut.edu.cn (J.C.); me_wangsr@ujn.edu.cn (S.W.); me_duandr@ujn.edu.cn (D.D.); xiaojupeng1113@163.com (J.X.); maidiyang123@163.com (W.L.)

* Correspondence: me_yangxf@ujn.edu.cn

Received: 3 January 2020; Accepted: 7 February 2020; Published: 13 February 2020

check for updates

\begin{abstract}
In this paper, a variety of micro-textures made by imitating the biological body surface are mentioned, and four common biomimetic texture types—convex hull, pit, groove and corrugation —are summarized by referring to a large number of literatures. These texture types that are widely used are those of the grooves and the pits of non-smooth surface because their viscosity drag reduction effects are relatively optimal for wear-resistance; in view of these two types of textures (with others including pit diameter, groove width, depth and area of share, and morphology spacing), we use data analysis and comparisons to find optimal parameter values in order to find the optimal effect of drag reduction and anti-sticking wear-resistance. Several texture processing methods are briefly introduced through case analysis and an illustration of the viscosity drag reduction mechanism of wear-resistance, and general fluid dynamic pressure is deduced from a theory formula in order to facilitate future research work on the basis of the optimal parameters to further improve the friction, wear lubrication, and hydrophobic properties, thus improving the bionic texture surface efficiency of saving energy and reducing consumption in industrial applications.
\end{abstract}

Keywords: bionic texture; viscosity and drag reduction; wear resistance mechanism; parameter optimization

\section{Introduction}

With the evolution of billions of years, the forms, structures, and functions of organisms in nature have been optimized [1]. With the development of science and technology, the loss of energy resources has gradually become serious. According to statistics, more than one-third of energy is consumed by friction. In order to achieve the purposes of energy saving and efficiency improvement, as well as to improve the performance of viscosity reduction, resistance reduction and wear resistance in the machinery industry, bionic tribology theory has been introduced in industrial production. Studies on surface texture properties, such as friction reduction, anti-adhesion, super-hydrophobic, anti-wear, and high-efficiency lubrication mechanisms [2-5], have broadened the research field and scientific basis of tribology. Bionic tribology can be divided into two categories: material bionics [6] and texture bionics [7]. Texture bionics is a texture that is processed on the surface of a friction pair to mimic the morphology of a biological surface. The research purpose of this paper was to improve the operation of friction drag reduction on the surface of a friction pair in the process of wear and lubrication performance through the analysis and summarization of experimental data in different working conditions in order to find the optimal texture parameters of texture design; this then allowed for an exploration of texture design' influence on the coefficient of friction and wear volume so that a desired surface performance, a further study of the tribological properties of materials, 
and improvements of the friction and wear mechanisms of the theory basis of the study of bionic texture could be achieved. Further research on the tribological properties of materials and the solving of the problems of friction and wear have great significance for China's sustainable development; they also have high academic value and broad application prospects. At present, the research of bionic textures is extensive. Types of bionic textures mainly include the pit, groove, convex hull, corrugation, scale, and even compound types. There are also very different types of texture parameters, processing methods, and drag reduction, and wear-resistant lubrication mechanisms. The following is a detailed introduction of several typical texture.

\section{Mechanism of Surface Impedance Reduction Wear and Theoretical Analysis of Fluid Dynamic Pressure}

\subsection{Impedance Reduction Grinding Mechanism of Micro-Pits/Grooves}

The pit texture requires the processing of various shapes on the surface of a friction pair; these shapes are arranged according to a certain rule. The workpiece generates a certain amount of frictional heat and abrasion during friction. In a scenario in which frictional heat is too large and cannot be used for a long time, there are several possible outcomes. If the heat dissipates, a mechanical knob is produced to damage the workpiece, and if the grinding debris is not processed in time, it causes severe friction on the surface of the friction pair, thus increasing the wear of the workpiece and reducing the service life of the workpiece. Additionally, the pit texture has a special pit structure that can store abrasive debris when the workpiece is in dry friction motion [8,9], thus avoiding the wear caused by abrasive debris and maintaining a clean and smooth environment during the entire movement; the pit type also has good resistance during oil lubrication because the lubricating oil can be stored in the pits. If friction time is too long, it inevitably leads to insufficient oil supply and a lack of oil. At this time, the lubricating oil that is stored in the pits is squeezed due to friction. The pressure squeezes the oil out of the pits to achieve the purpose of secondary lubrication, which reduces the frictional resistance and also reduces the amount of wear.

The groove texture is a densely arranged array structure that is processed on the surface of a workpiece. When the friction direction is parallel to the groove direction, it produces a unidirectional convergence effect, and, especially under oil lubrication conditions, the convergence area produces a strong dynamic pressure and dynamic pressure effect $[10,11]$. Avoiding direct contact between the rough peaks can effectively reduce wear; additionally, the design of the groove texture can also reduce the contact area between friction pairs, and if the abrasive particles are not lubricated in time, micro-cutting occurs on the surface. In severe cases, the particles are brittlely exfoliated after severe extrusion, and the workpiece is damaged. The groove can also achieve a secondary oil supply and dynamic pressure lubrication, which not only reduce frictional resistance but also greatly reduce the amount of wear.

\subsection{Universal Theory of Hydrodynamic Lubrication Based on Couette Flow}

There are two mechanisms of fluid lubrication: One is the artificial input of lubricating oil between the surfaces, which balances the external load so as to separate the contact surfaces-this is called hydrostatic lubrication. In the second method, the relative motion of a friction pair is used to bring the lubricating oil into the friction surface to form a pressure oil film to separate it, this is called hydrodynamic lubrication. In general, each micro-morphology on the friction pair surface has a fluid dynamic pressure distribution, and the two parallel surfaces are separated by oil film. Such micro-morphology has wedge micro-convex hull, micro-concave pits, and a micro-groove, all of which play a role in the "wedge micro-bearing" in the process of dynamic pressure lubrication (as shown in Figure 1). 


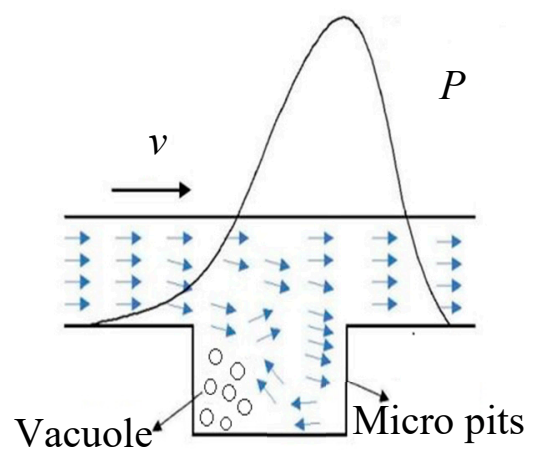

(a) Micro pits

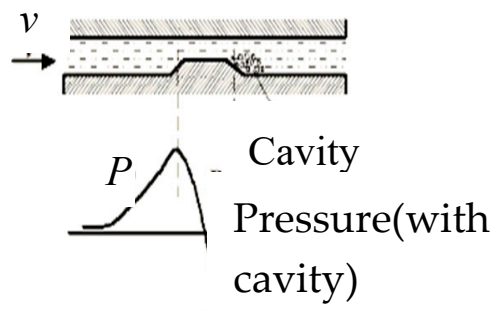

Pressure (without cavity)

(b) Micro bulge

Figure 1. Dynamic pressure lubrication.

Hydrodynamic lubrication is often accompanied by cavitation, where the fluid velocity sharply changes at the divergence end, so negative pressure occurs. When the negative pressure breaks the critical value, cavitation occurs. Cavitation and fluid dynamic pressure act on both sides of the micro-pit unit so that the fluid on the unit has a "net" positive pressure and the lubrication film has a certain bearing capacity $[12,13]$. When the fluid that is affected by the micro-crater passes through the right side of the crater, the liquid flux increases, and an additional supporting force is applied to the surface to increase the thickness of the oil film. The following equation is the simplified Navier-Stokes equation in the form of Couette flow:

$$
\frac{V_{x}(y)}{y}=U \frac{1}{h_{0}}-\frac{1}{2 \mu} \frac{d p}{d x}\left(h_{0}-y\right)
$$

where $P=d p / d x$. Equation (2) represents the relationship between fluid velocity and pressure, and there are no parameters that represent friction and the coefficient of friction, so this equation needs to be related to the coefficient of friction and other parameters through an intermediate equation. Therefore, by substituting the equation into a pressure-friction conversion equation (Equation (3)), Equation (4) is obtained.

$$
\begin{gathered}
f=\frac{\frac{d p}{d x \cdot\left(D_{1}+D_{2}\right)}\left(D_{1}^{2}-D_{2}^{2}\right) \pi}{n}=\frac{\frac{d p}{d x}}{n}\left(D_{1}-D_{2}\right) \pi \\
f=\frac{\frac{U}{h_{0}}-\frac{V_{x}(y)}{y}}{\left(h_{0}-y\right)} \cdot \frac{2 \mu}{n} \cdot\left(D_{1}-D_{2}\right) \pi
\end{gathered}
$$

where $d p / d x \cdot\left(D_{1}-D_{2}\right) / n$ is a unit area of the pressure value, $n$ is the experimental specimen surface texture distribution of the number, $D_{1}$ is used for the experimental value of the grinding head outer diameter, $D_{2}$ is the experimental value of the grinding head inner diameter, $h_{0}$ is oil film thickness 
between two motion friction pairs, $\mu$ is the dynamic viscosity, $U$ is the power for the plate movement speed, $y$ is the film thickness direction of the independent variable, and $\frac{V_{x}(y)}{y}$ is the lubricating oil flow velocity in the $X$ direction of first order partial derivative. Equation (4) is used for friction and fluid flow characteristics, and the relationship between the coefficient of friction is the ratio of loading force and friction force; as such, there is a need to continue equation. Thus comes Equation (5) which shows the relationship between the coefficient of friction and fluid mechanics parameters.

$$
\frac{F}{f}=\frac{P \cdot S}{f}=\frac{P \cdot S\left(h_{0}-y\right) \cdot n}{\left(\frac{U}{h_{0}}-\frac{V_{x}(y)}{y}\right) \cdot 2 \mu\left(D_{1}-D_{2}\right) \pi}
$$

where $S$ is the actual contact area between the grinding head and the specimen in the experiment, and $P$ is the internal pressure of the lubricant fluid that is obtained from the loading force and the actual contact area in the experiment. The ratio of the product to the friction force is the coefficient of friction.

\section{Biomimetic Microtextured Surfaces}

\subsection{Revelation of Nature}

Figure 2 shows some typical organisms and their micro-textured surfaces. Soil organisms (earthworms [14], dung beetles, and pangolins) crawl and move in the soil throughout the year. They do not stick to the soil, cannot be hurt by hard stones, and can keep moving steadily while keeping themselves clean, mainly due to the special texture morphologies of their body surfaces; a non-smooth texture morphology has anti-adhesion, drag reduction, and wear-resistant performance, as well as a self-cleaning function. According to the special functionality of the body's surface, non-stick pans and bionic ploughshares are imitated. Aquatic creatures (sharks) need to overcome the resistance of water flow to maintain high-speed movement in order to prey and avoid natural enemies. A more severe test, relying on the uniformly distributed groove structure on the surface of the body, can reduce turbulence while reducing shear stress and greatly reducing resistance to water movement, thus increasing the speed. The researchers imitated this characteristic which is also found sharkskin swimsuits; there are also some flying animals (spike tail swifts and butterflies) that need to overcome air resistance while ensuring the speed of flight, and their body textures can also be used for special weather such as rain or snow. This texture allows for an animal to fly as usual without being hit by raindrops. Its feather structure has not only a drag reduction function but also a certain hydrophobic performance. This microstructure is applied to the surface of automobile aircraft to achieve energy savings and consumption reductions. The appearance is designed to improve lift; in addition, some plants (lotus and Nepenthes) show strong hydrophilia/hydrophobicity and self-cleaning abilities, which makes them worthy of further exploration by researchers.

Through observation and research on earthworms, dung beetles, sharks, lotus leaves and other organisms, it has found that a non-smooth texture morphology at the micro/nano scale exists on the surface of these organisms (see Figure 3 [15]). Figure 3a is an SEM diagram of the pit texture, as represented by the body surface of a dung beetle. Pits in the beetle's back reduce resistance. Figure $3 \mathrm{~b}$ is an SEM diagram of a convex hull texture. For example, there is a similar micro-texture on the surface of the lotus leaf. Figure $3 c$ shows the microstructure of a corrugated texture. The surface of an earthworm is such a structure, which can achieve self-cleaning and resistance reduction. Figure $3 \mathrm{~d}$ shows the groove texture of a typical shark body surface, which has the functions of reducing drag of storing grinding debris and secondary lubrication when applied to industries. 


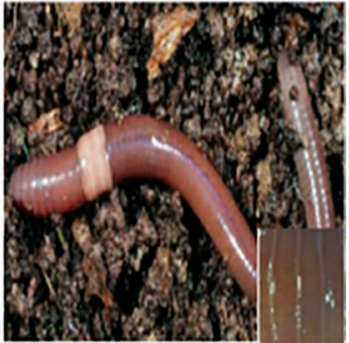

(a) Earthworm

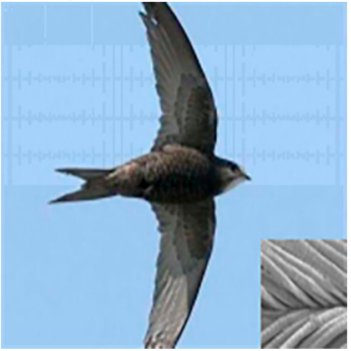

(e) Swift

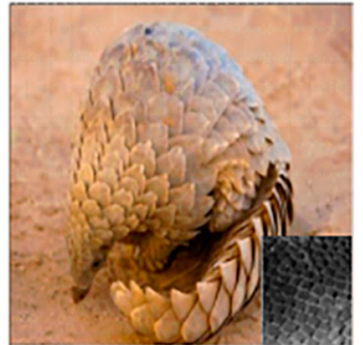

(b) Pangolin

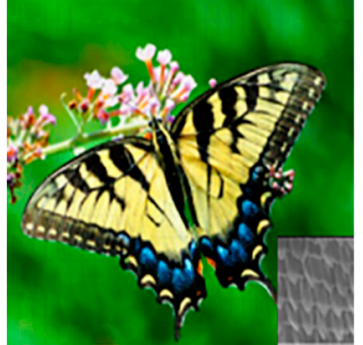

(f) Butterfly

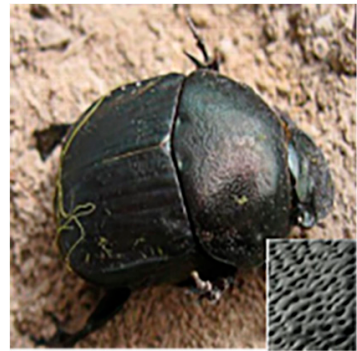

(c) Dung beetle

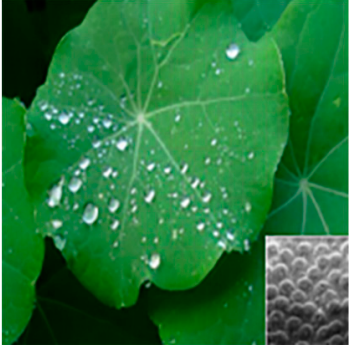

(g) Lotus leaf

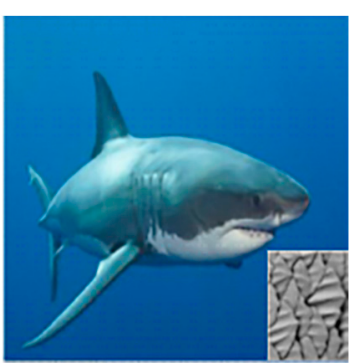

(d) Shark

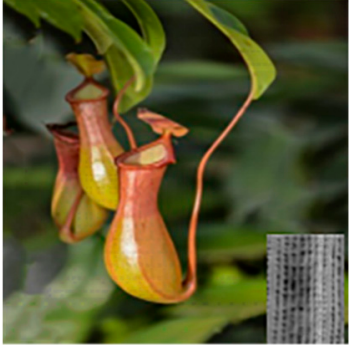

(h) Nepenthes

Figure 2. Micro-textured morphology of typical organisms and surfaces.
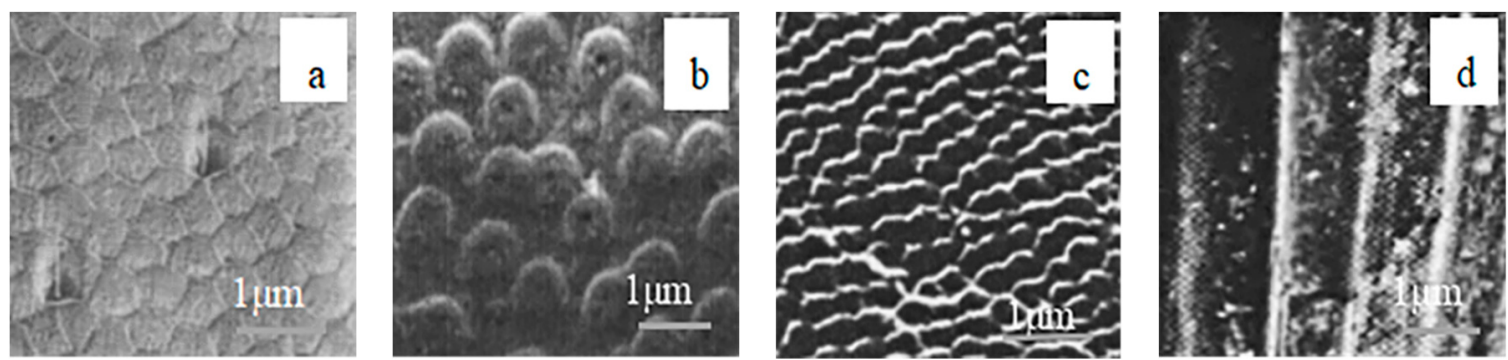

Figure 3. Non-smooth texture. (a) Pit; (b) convex hull; (c) corrugation; and (d) groove.

\subsection{Research Status of Two Widely Used Biomimetic Textures}

The most widely studied textures are those of the pit and groove types, which have good effects of reducing viscosity and resistance. For example, Tan A et al. [16] designed and processed a bionic pit-type texture on the surface of a drilling mud pump piston, and they found that this texture was could significantly improve the service life of the piston. Yu et al. [17] explored the optimization of the parameters of the groove texture with reference to shark skin. Research on surface textures has shown that [18] the shape, direction, size and working conditions of textures have a great impact of the tribological properties on texture surfaces. AHMED A et al. [19] used the basic geometry of the groove texture to design and process parameters of depth, width, and pitch, multi-scale groove textures with various gradient changes.

\section{Surface Texture Processing Technology}

In recent years, the study of the tribological properties of bionic textures has reached a new level, but the study of tribological properties is closely related to the processing technology of surface texture. The maturity of processing technology deeply affects research results. Therefore, research on processing technology is also crucial. Processing technology is mainly divided into micro-cutting processing technology, electrolytic processing technology, electric discharge machining technology, reactive ion etching processing technology, micro-abrasive jet processing technology, and laser surface texture technology [20,21]. Among them, reactive ion etching and laser surface texture technology are the most widely using. 
(1) Micro-cutting processing technology refers to a technology that uses a special processing tool and a specific processing machine to process a small texture with a certain shape and size on the surface of a workpiece. The requirements for cutting tools and machine tools are high, especially the hardness and wear resistance of the cutting tool, and the anti-adhesion to the workpiece is better. This processing technology has the advantages of a high efficiency and wide processing range.

(2) Electric discharge machining (EDM) technology refers to a special processing technology that uses the high temperature generated by EDM to melt the surface of a workpiece to produce the required texture. The purpose of material removal is achieved by the electric erosion effect that is formed by the pulse discharge between the two electrodes. D.P. Chowdhury et al. used EDM technology to study process methods. Anonymous et al. [22] studied EDM technology through experiments and obtained an optimal combination of electrical parameters that greatly improved efficiency.

(3) Electrolytic processing is a processing technology that uses the principle of the electrochemical anode dissolution of metallic materials in electrolytes to form anode workpieces. It has many advantages, such as a good processing quality, a wide range, and high efficiency. The method is costly. Some domestic and foreign scholars have proposed the use of an electrochemical machining method to remove sample metal materials to get the pits and to clean the surface mask to obtain a sample with a desired surface texture. This method can improve the friction performance, wear performance, and service life of mechanical seals.

(4) Reactive ion etching (RIE) is an etching method based on physical and chemical reactions. After the ions that are generated in the ion source are extracted, they are accelerated and focused to form an ion beam, which impacts the workpiece surface in a vacuum and uses its kinetic energy for processing [23]. Compared with LIGA (Lithogrophy electroforming micro molding) technology, RIE technology can perform engraving at less than $50 \mathrm{~nm}$ at a relatively fast direct write speed, and it is a computer-controlled mask-free injection without development etching that enables the directly fabrication of various nanodevice structures. RIE technology is a suitable choice for the preparation of small-scale and high-precision micro-textures in laboratory experiments. However, there are also some problems in the processing process of RIE technology such as the prominent damage that is created, the difficulty in controlling the ion beam processing precision, a control precision that is not high enough, and the requirement of expensive experimental environment. Additionally, the initial basic experimental equipment of this technology is expensive, the whole production cycle is long, and the process is complex. In terms of cost and efficiency, RIE technology is still slightly flawed $[24,25]$. Before processing, a photoresist mask is usually made on the surface of the workpiece by using traditional photolithography technology to protect the surface before processing. This technique has strong anisotropy and high selectivity. The entire processing process needs to be performed in a vacuum environment, which also increases its cost.

(5) Micro-abrasive jet processing technology is mainly divided into micro-abrasive air jet processing technology and micro-abrasive water jet processing technology. High-pressure air or water is used as the medium to drive the micro-abrasive to form a high-pressure jet in a special nozzle. The interaction between the abrasive particles and the work piece can achieve the effect of material removal, which is suitable for the micro-cutting and polishing of hard, brittle, and composite materials. However, the jet diffusion phenomenon exists. When the jet distance is large, the size and surface quality of the processing area are not easy to control. Therefore, this processing method can be used to process simple grooves and small-size micro-textures at a small jet distance [26-28].

(6) Laser surface texture (LST) technology is a kind of the nanosecond modelling of femtosecond lasers in micron or nanometer level surface processing technology; it can produce all kinds of precise shapes that are flexible in complex surface textures, its size control ability is strong, and its manufacturing processing speed is fast. Thus, the LST is one of the more successful methods, 
it is the most widely used surface micro texture technology [29,30], and it has the advantages of environmental protection and no "tool" wear. Since the laser equipment itself is relatively expensive compared with general processing equipment and the environmental requirements in the actual processing process are higher, the initial and later costs of LST technology are relatively high. In addition, after LST processing, there are bumps on the surface that require later polishing or chemical treatment, thus increasing the workload and cost. Third, due to the high energy density of laser, LST technology inevitably causes associated damage to the surrounding surface of the texture, and, due to the penetrability of light, LST technology cannot be used for transparent or other materials with special optical properties. These insurmountable defects also limit the development of LST technology in practical applications [31]. GOYA K et al. [32] gave a detailed review of femtosecond laser processing at home and abroad. Mistry V et al. [33] used finite element simulation technology to analyze key process parameters in liquid-assisted laser beam micromachining. Ahmmed K M T et al. [34] studied laser processing technology in regards to the grooves on the surface of a complex curved surface-parameters such as laser power and scanning frequency were experimentally compared to determine optimal parameters.

\section{The Effect of Texture Size on Frictional Wear Property}

\subsection{Pit Diameter}

A reasonable pit texture can reduce wear and improve bearing capacity because of the texture's function of storing abrasive debris and secondary lubrication $[35,36]$. However, a specific effect must be considered in combination with actual working conditions. The friction reduction mechanisms of the pit texture under oil lubrication and dry friction are very different [37-39]. In the past, the shape, size, effect of depth, etc., on friction and wear performance $[40,41]$ have had little attention pad to them in regards to surface texture under the conditions of dry friction and spent oil. In long-term, high-speed operation, running out of oil is inevitable, and an insufficient oil supply may lead to a sudden rise in the temperature between friction pairs and the instantaneous failure of the workpiece. In order to ensure that a workpiece has a certain life in the case of lubrication failure, it is of great significance to study friction and wear in cases of dry friction and spent oil.

Figures 4 and 5 show SEM images of four different diameters of pit texture [42,43] as $10 \mu \mathrm{m}, 50 \mu \mathrm{m}$, $100 \mu \mathrm{m}$, and $150 \mu \mathrm{m}$ that were achieved with a laser processing method under the dry friction and spent lubrication oil conditions, respectively during the friction and wear experiments. Mainly abrasive and adhesive wear can be seen from the diagrams, with both being visible in Figure $4 a-c$, where the pit diameter was refined grain and the wear was more serious. One can also see a little of flake material, and the diameter of the pit in Figure 4d, Figure 4e had a lighter abrasive wear lighter compared with the other figures. Figure 4e mainly shows obvious adhesive wear, because the larger the pit diameter is, the more dust can be stored to avoid abrasive wear.

Figure 5 shows surface micro-morphologies under oil-depleted conditions. Under abrasive conditions, abrasive grains are mainly used. Figure 5 a shows the micro-morphology of a non-textured surface. Here, the grain and peeling pits were more severely worn; the diameter of the pits in Figure $5 \mathrm{~b}$ was $10 \mu \mathrm{m}$, and their spacing was small and their degree of wear is light, because a large number of pits can form a continuous lubrication film that has a good lubrication effect. The adhesion on the surface of the texture shown Figure $5 c$, Figure 5 e was lighter, mainly due to abrasive wear, the degree of which was not very serious. However, in Figure 11d, furrows can be clearly seen, and these were accompanied by spalling pits with slight adhesive wear. 


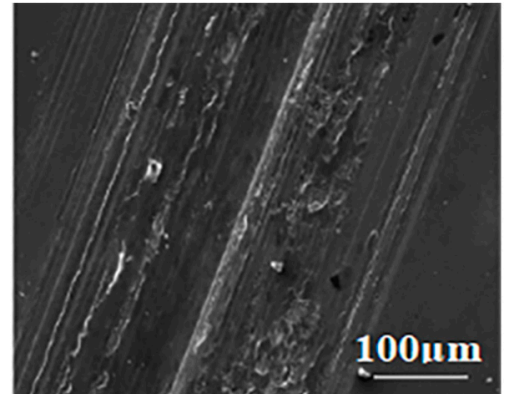

(a) No texture

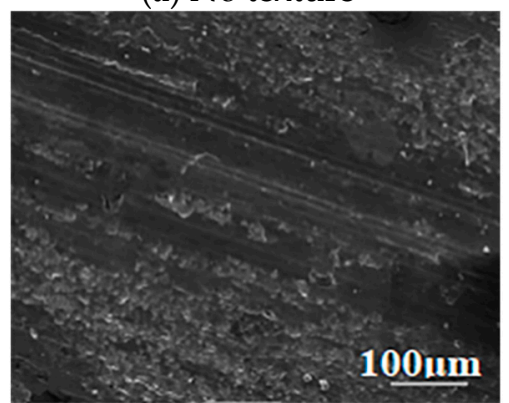

(d) $100 \mu \mathrm{m}$

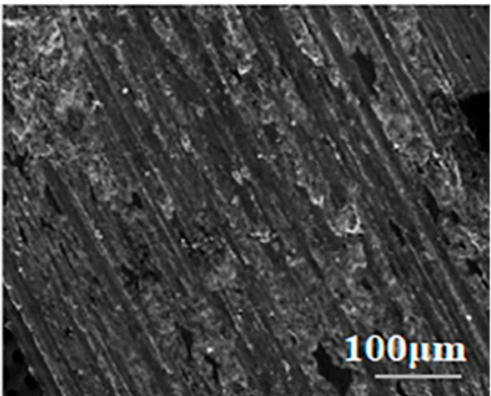

(b) $10 \mu \mathrm{m}$

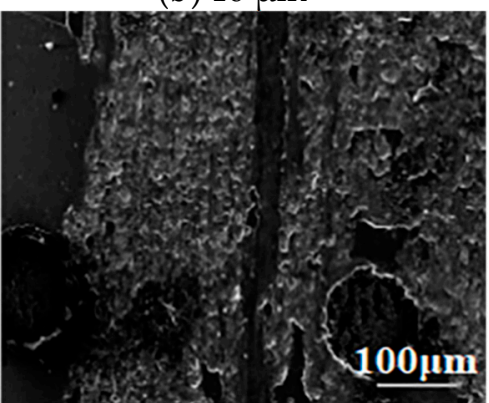

(e) $150 \mu \mathrm{m}$

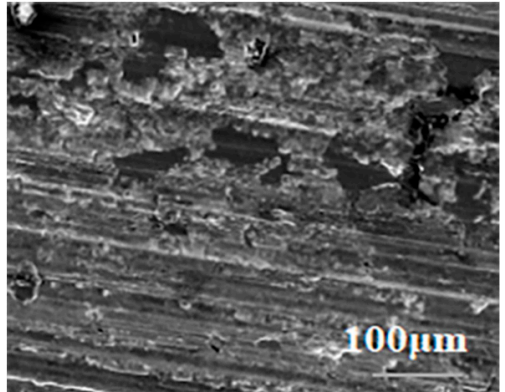

(c) $50 \mu \mathrm{m}$

Figure 4. Microscopic morphology of wear scars of different pit diameters under dry friction.

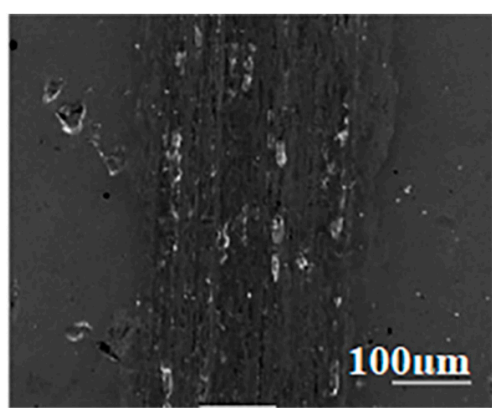

(a) No texture

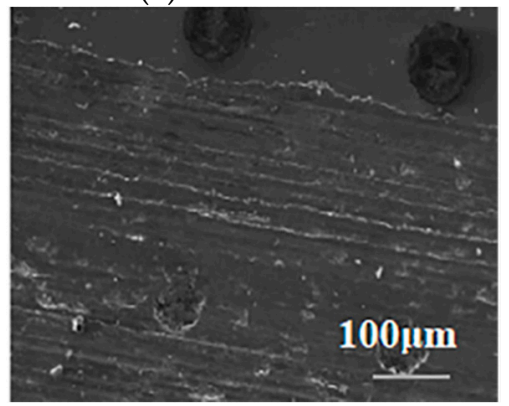

(d) $100 \mu \mathrm{m}$

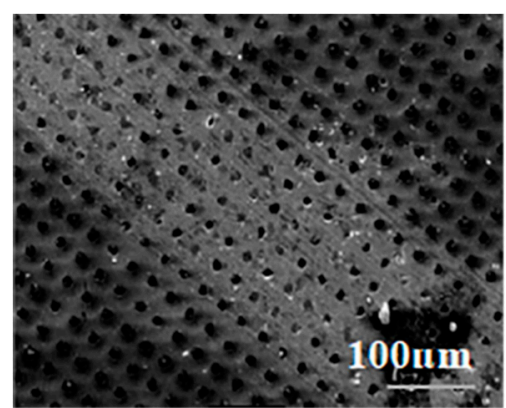

(b) $10 \mu \mathrm{m}$

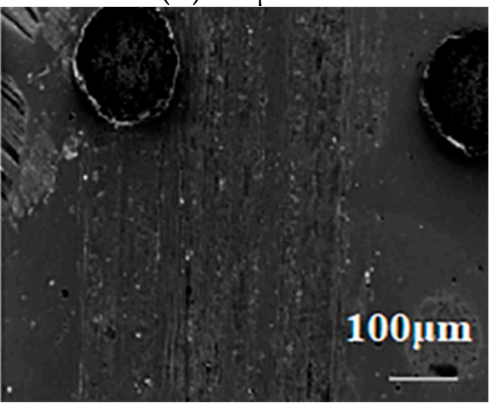

(e) $150 \mu \mathrm{m}$

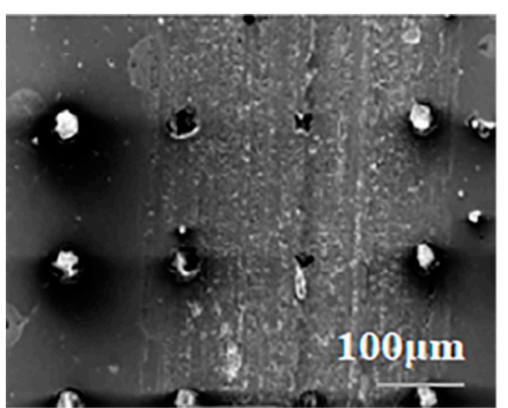

(c) $50 \mu \mathrm{m}$

Figure 5. Microscopic morphology of wear scars of different pit diameters under oil shortage.

After observing friction and wear experiments, it could be concluded that pit diameter, under the conditions of dry friction, drag reduction, wear resistance, does not have a large effect, because no lubrication effects of the dry friction itself, roughness or diameter produce any large reduction values during the processes of wear and tear. However, with an increase of diameter, the same area of the unit may reduce the number of pits, thus moving further from abrasive wear to adhesive wear and leading to decreased wear and tear. Under the condition of a lack of oil, a $10 \mu \mathrm{m}$ pit diameter leads to the best reduction of wear-resistance effect, and a larger the diameter leads to worse effects. This is because a small diameter, a small number of pits, and small indentation spacing make it easy to form a 
continuous state of lubricating film under a lack of oil, all of which increase the lubrication effect and decrease the friction coefficient and wear rate.

\subsection{Pit Depth}

Dimples of a certain shape and depth can have drag reduction effects under certain lubrication conditions. During the friction process, due to design and actual working conditions, there may be an oil shortage. Pits with different depths were machined on the surface of a friction pair, and their effects on the lubrication effect were analyzed through experiments. The samples with depths of 1,3 , and $5 \mu \mathrm{m}$ were selected, and the friction factors were analyzed under the conditions of loads of 100, 200, and 300 N. From Figure 6, it can be seen that the coefficient of friction at each depth appeared as the load increased. There was decreasing trend, indicating that the magnitude of the load had almost no effect on the friction coefficient of the different pit depths, and the magnitude had a relationship with the pit depth itself, but this relationship did not increase or decrease non-linearly. A measurement of the coefficient of friction was taken at a depth of $3 \mu \mathrm{m}$. The minimum value exceeded this depth, and the coefficient of friction again increased. This was because the pit texture could store not only lubricating oil but also micro-bubbles during friction in the absence of oil; as such, the gas participated in lubrication and loading, and then it changed the contact. Physical properties, such as the viscosity of the oil film, should be adjusted so that the pits are not too deep or too shallow.

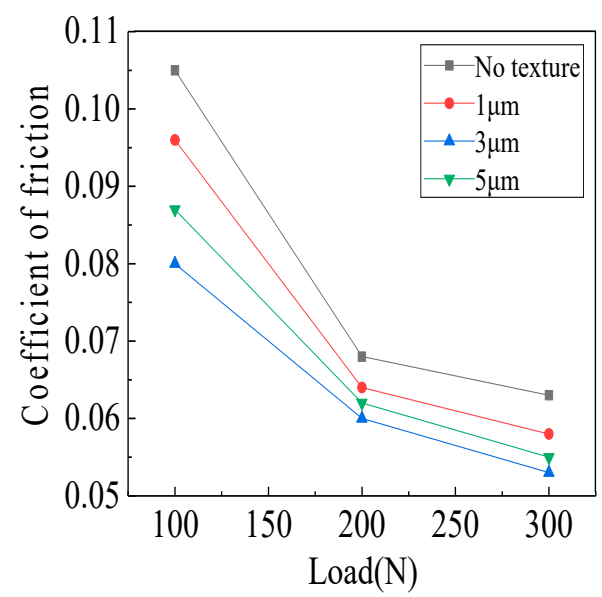

Figure 6. The coefficients of friction corresponding to each pit depth under different load conditions.

\subsection{Groove Width}

A large number of experimental analyses showed that micro texture has the effect of reducing the coefficient of friction and wear of the surface of a friction pair. The final effect depends on a number of factors, including groove width, pitch, density, applied load, and substrate material. Groove width [44] has been found to have a certain effect on the coefficient of friction. Under certain conditions, a reasonable arrangement of groove width can effectively improve secondary lubrication, thereby reducing the coefficient of friction. At present, there are four main types of bionic texture base materials: \#45 steel [29], gray cast iron [45], high-speed steel [46], and cemented carbide [47]. The base material also has a great influence on drag reduction and wear resistance. The specific effects of base materials still need to be explored in depth. Samples with widths of 60,120, and $180 \mu \mathrm{m}$ were selected. A comparison was made between $45 \#$ steel $(150 \mathrm{~N})$, gray cast iron $(300 \mathrm{~N})$, high speed steel $(450 \mathrm{~N})$, and hard alloy $(600 \mathrm{~N})$ with pitches of 70,135, and $200 \mu \mathrm{m}$. The analysis of the coefficient of friction is shown in Figure 7. 


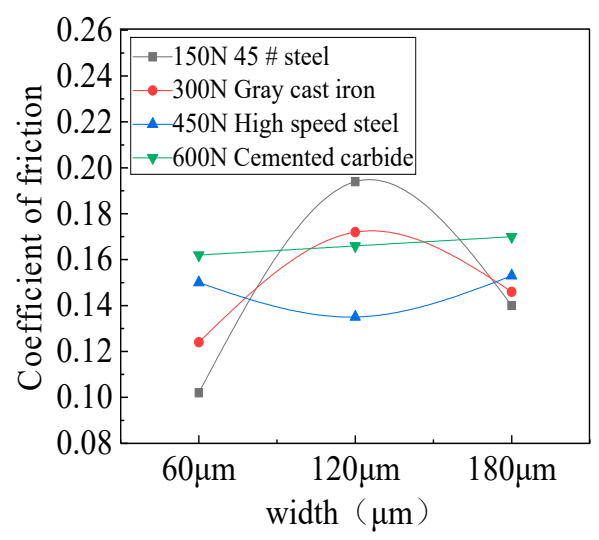

(a) Spacing $\mathrm{L}=70 \mu \mathrm{m}$

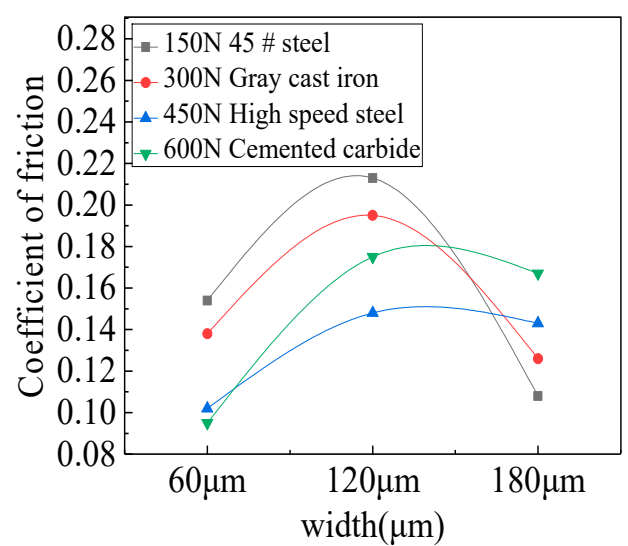

(b) Spacing L = $135 \mu \mathrm{m}$

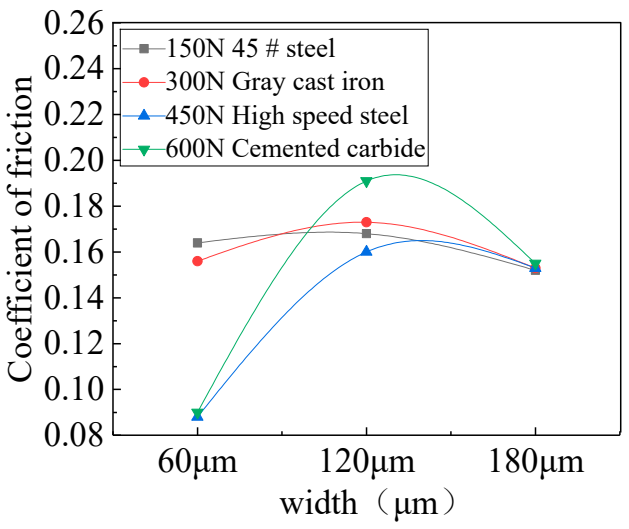

(c) Spacing $\mathrm{L}=200 \mu \mathrm{m}$

Figure 7. Effect of width on the coefficient of friction under different spacings.

It can be seen from Figure 7a that when the distance was $70 \mu \mathrm{m}$, the coefficient of friction under each load changed irregularly with the increase of the width, indicating that the influence of the distance and load on the coefficient of friction was obvious at this time. When the distance was constant, a small width and a low load that effect of drag reduction was the best; Figure $7 \mathrm{~b}$ shows the coefficient of friction measured at a distance of $135 \mu \mathrm{m}$. It first increased and then decreased with the increase of the width. Compared with Figure 7a, the distance increased, and the $600 \mathrm{~N}$ load achieved a minimum value at a small width. Because the number of grooves decreased with the increase of the distance, a larger load was required during the friction process to form a dynamic pressure lubrication effect between the grooves, and the oil in the grooves was squeezed out to achieve lubrication and drag reduction; Figure 7c shows the same trend as that of Figure 7b, and the mechanism was the same here. However, when the width was $60 \mu \mathrm{m}$, the coefficient of friction was very different, and when the width was $180 \mu \mathrm{m}$, the four loads converged to one point. This indicates that at this interval, it is not appropriate to have a large width. No matter what the load was, the friction effect at this width the significance was not great, because the excessive width did not highlight the advantage of texturing, instead forming a furrow on the surface that defeated the purpose of the research. In summary, no matter how big the load or pitch was, a width of $60 \mu \mathrm{m}$ was able to achieve the minimum coefficient of friction and the best drag reduction effect. 


\section{The Effect of Texture Spacing on Frictional Wear Properties}

\subsection{Pit Spacing}

Research on the effects of the texture of pits on friction and wear performance has not only considered the diameter of the texture and depth but also the distance between textures. It has been found that appropriate texture spacing can have good wear resistance effect and that there are certain differences in the drag reduction of wear-resistance under different working conditions. In view of the research that has been done to achieve precise values, we attempted to select appropriate spacing selections of 20 and $30 \mu \mathrm{m}$. A traditional lubricating oil extraction process that consumes resources also produces pollution to the environment; thus, to improve this situation, many researchers have considered friction and wear under the conditions of water and seawater. The coefficient of friction and wear capacity were compared under the lubrication conditions of seawater and oil [48], and the results are shown in Table 1 and Figure 8.

Table 1. The coefficients of friction of pits with different pitches.

\begin{tabular}{cccc}
\hline Coefficient of Friction & Textureless Surface & Spacing $20 \boldsymbol{\mu m}$ & Spacing $\mathbf{3 0} \boldsymbol{\mu m}$ \\
\hline Water & 0.549 & 0.502 & 0.527 \\
Seawater & 0.493 & 0.465 & 0.479 \\
Oil & 0.442 & 0.177 & 0.198 \\
\hline
\end{tabular}

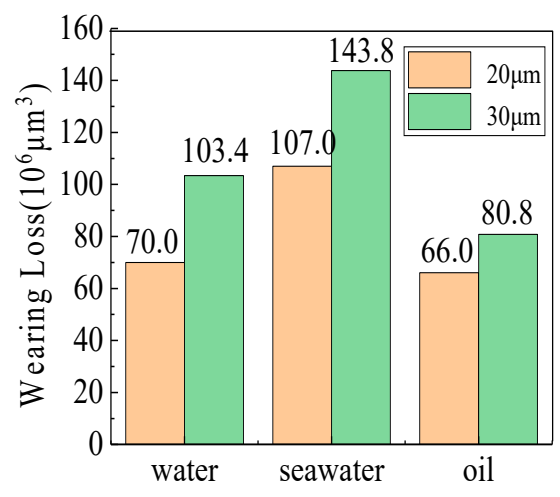

Figure 8. Wear loss of pit surfaces with different spacings.

As shown in Table 1, the coefficient of friction of the sample with a distance of $20 \mu \mathrm{m}$ reached a minimum value under oil lubrication. Compared with a smooth surface, the surface coefficient of the friction of the pit texture had a larger change, but the coefficients of friction of the two distances were different. This indicates that micro textures must be set on the surface in order to achieve the effect of drag reduction and wear resistance, and different texture intervals have little effect on the coefficient of friction; from the analysis of the wear amount in Figure 8, it can be seen that the two distances under three lubrication conditions the change trend were the same, and the minimum wear amount of the $20 \mu \mathrm{m}$ pitch was reached under oil lubrication. Corresponding to the results in Table 1, because there were more pits with $20 \mu \mathrm{m}$ pitches, the fluid lubrication effect was more obvious, and this effect was able to effectively avoid the roughness of the friction pair between peaks. As far as lubrication conditions are concerned, seawater is rich in various ions that are corrosive and abrasion-based [49]. The metal chlorides $\mathrm{FeCl}_{2}$ and $\mathrm{CrCl}_{3}$, as well as the salts $\mathrm{CrO}_{2}{ }^{2-}$ and $\mathrm{CrO}_{4}{ }^{2-}$, have the effect of reducing friction and abrasion. Salinity in seawater also affects the amount of wear; there may be oxidative wear in water that increases the coefficient of friction and amount of wear, so oil lubrication has the best chance of reducing drag and abrasion. 


\subsection{Groove Spacing}

Similarly, samples with distances of 70, 135, and $200 \mu \mathrm{m}$ were selected to analyze the effect of the load on the coefficient of friction at a certain distances under different width conditions. In Figure 9, the abscissa represents groove spacing, the ordinate represents the coefficient of friction, and each curve represents a different load.

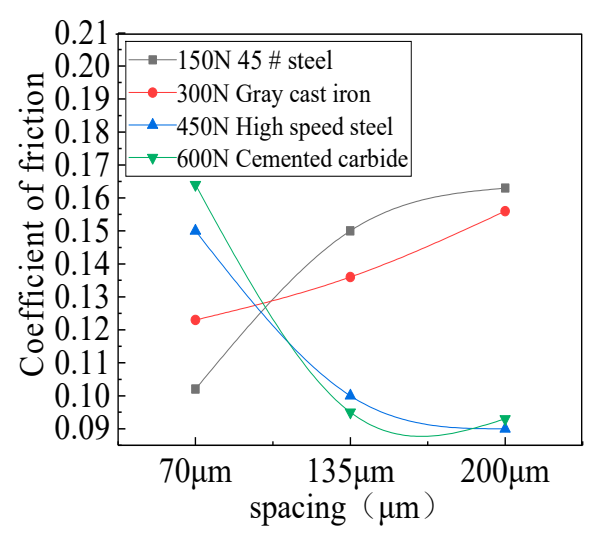

(a) Width $\mathrm{M}=60 \mu \mathrm{m}$

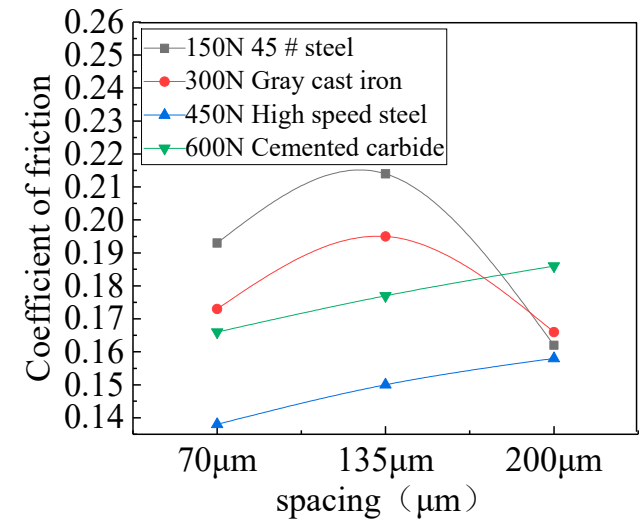

(b) Width $\mathrm{M}=120 \mu \mathrm{m}$

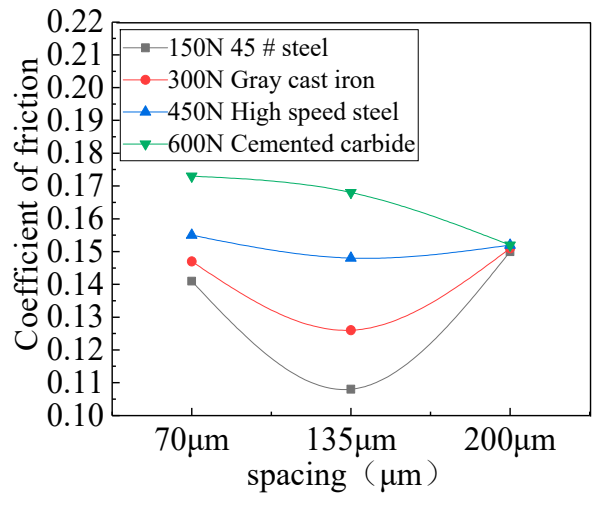

(c) Width $\mathrm{M}=180 \mu \mathrm{m}$

Figure 9. Effect of spacing on the coefficient of friction under different widths.

As can be seen from the above figure, groove spacing had a significant effect on the coefficient of friction of the texture, and this effect is corroborated by Figure 9. In Figure 9a, the curve of the four loads varied greatly. The coefficient of friction of the 150 and $300 \mathrm{~N}$ loads varied with increasing distance, and the coefficients of friction of the 450 and $600 \mathrm{~N}$ loads gradually decreased and reached minimum value at $200 \mu \mathrm{m}$. This indicates that when the distance is larger, a larger load can form a good fluid dynamic pressure effect, thereby reducing friction when the distance is small. Additionally, and excessive load can rupture an oil film and reduce its bearing capacity, which does not help to reduce friction. It can be seen in Figure $9 b$ that the trend of the coefficient of friction of each load was also irregular. It can be said that the $450 \mathrm{~N}$ test piece achieved a minimum value at a distance of $70 \mu \mathrm{m}$. In Figure 9c, the curves of the 150 and $300 \mathrm{~N}$ loads are relatively smooth and their change rates are small, which indicates that the groove spacing under these two loads had a small effect on the coefficient of friction. Additionally, the curve change rates of the $450 \mathrm{~N}$ and $600 \mathrm{~N}$ loads are relatively large, showing a trend of first decreasing and then increasing; the coefficient of friction was the smallest and the friction reduction effect was the best at $135 \mu \mathrm{m}$. In summary, the optimal value was not obtained when only distance was considered. Each parameter had a certain effect on the coefficient of friction. Therefore, it is necessary to choose an appropriate groove distance and comprehensively analyze the parameters, operating conditions, and the material itself. 


\section{The Effect of Texture Occupancy on Frictional Wear Properties}

\subsection{Pit Occupancy Rate}

This section comprehensively analyzes the friction characteristics of the pit texture test specimens under different area occupancy rates [50,51]. In addition to the texture morphology parameters, the speed, experimental force and area occupancy were found to synthesize the coefficient of friction of the test specimen. Figure 10 is Schematic diagram of pit texture. From the histogram below, it can be seen that the formula for the area occupation rate is:

$$
r=\frac{\pi D^{2}}{4 L^{2}}
$$

Here, $r$ is the area occupation rate, $D$ is the dimple diameter, and $L$ is the adjacent pit distance.

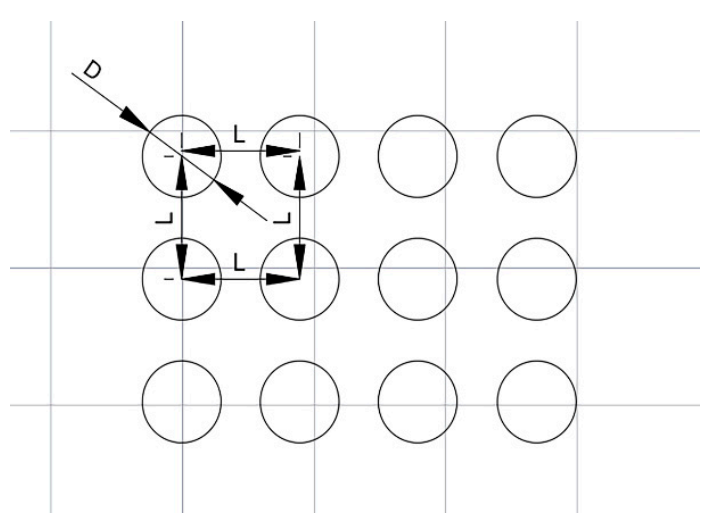

Figure 10. Schematic diagram of pit texture.

As shown in Figure 11, the area occupancy rate had a very significant effect on the friction characteristics of the test piece. The occupancy rate of $14.8 \%$ had a generally higher effect than that the area occupancy rate of $19.6 \%$ and $25.3 \%$. Under different working conditions with different speeds and experimental forces, the texture surface with an occupancy rate of about $20 \%$ had a relatively low coefficient of friction value. In addition, the coefficients of friction of the test pieces with different area occupancy ratios under low speeds and load capacities were generally much higher than the coefficient of friction values under high speeds and load capacities. The effect was obvious. The high rotation speed promoted the effective output of the lubricating oil in the pit, thus realizing the timely supply of the oil body between the friction pairs and the high continuity of the fluid flow, and this reduced the surface coefficient of friction. At the speed of $40 \mathrm{r} / \mathrm{min}$, each occupancy rate linearly decreased with the increase of experimental force. There was no such trend at other speeds. The lowest coefficient of friction at each speed was around $300 \mathrm{~N}$. At $180 \mathrm{r} / \mathrm{min}$ with an occupancy rate of $19.6 \%$, the coefficient of friction reached its lowest value. 


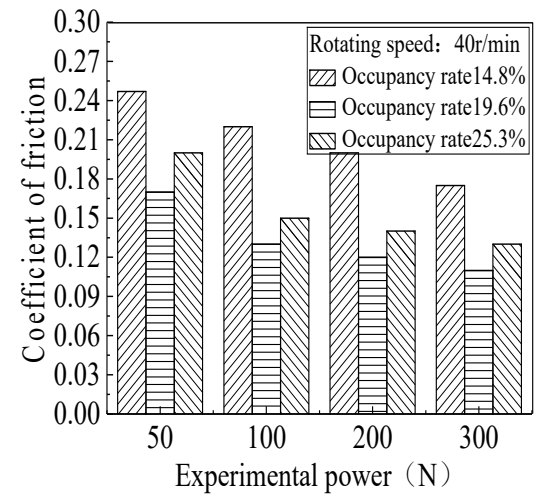

(a) Rotate speed of 40 (r/min)

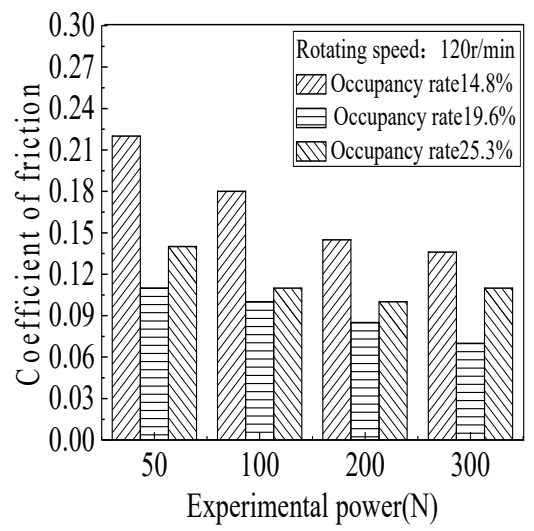

(c) Rotate speed of 120 (r/min)

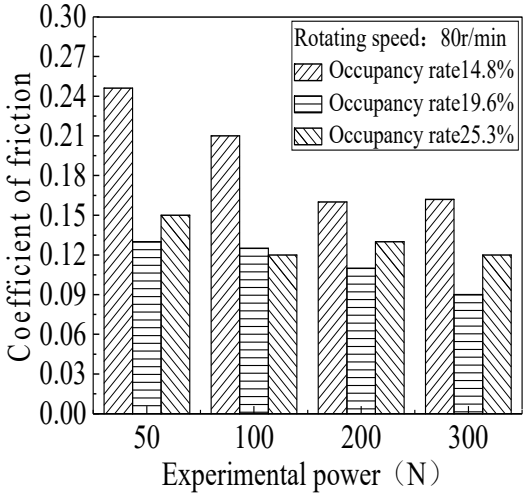

(b) Rotate speed of 40 (r/min)

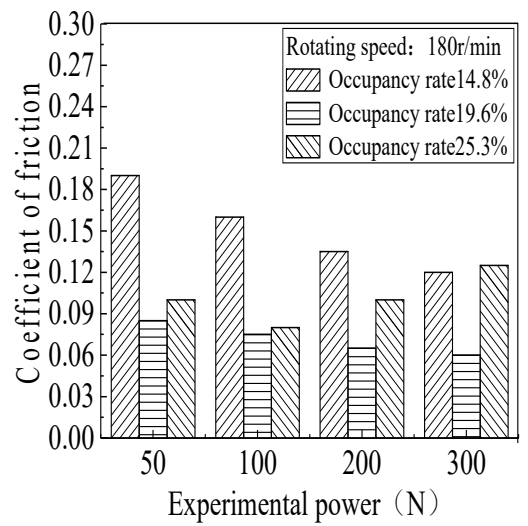

(d) Rotate speed of 180 (r/min)

Figure 11. Coefficients of friction corresponding to different occupancy rates.

\subsection{Groove Occupancy Rate}

The area occupancy is the density distribution of the texture elements on the surface of a friction pair. Generally, multiple rectangles are regularly arranged in order to form the texture region of the groove shape, as shown in Figure 12. The formula for the area occupancy per unit area is:

$$
\gamma=\frac{B}{(2 B+l)}
$$

Here, $\gamma$ is the area occupation rate, $B$ is the groove width, and $l$ is the groove spacing.

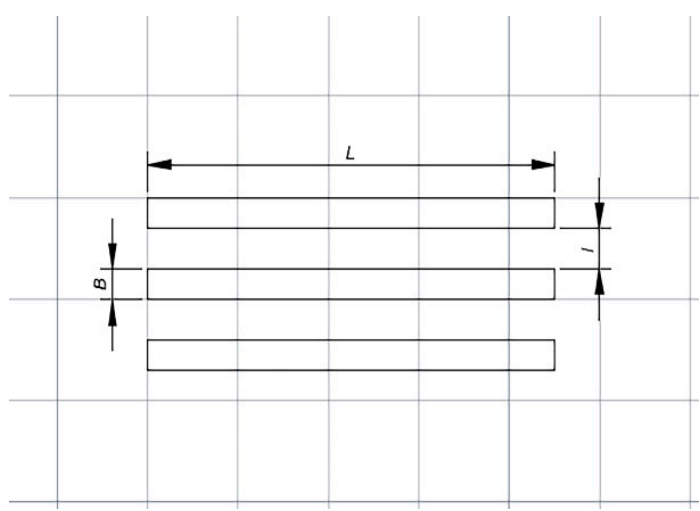

Figure 12. Schematic diagram of groove texture. 
The impacts of the occupancy rates of $0 \%, 23 \%, 37 \%$, and $46 \%$ on the coefficient of friction can be seen in Figure 13. The coefficient of friction of the $150 \mathrm{~N}$ output load increased with the increase of the density. The other three loads showed a trend of rising, then falling, and then rising, and all had a minimum value at a density of $37 \%$. The coefficient of friction of the $450 \mathrm{~N}$ load was the smallest. The effect of reducing friction was the best with the $450 \mathrm{~N}$ load, so when designing the texture layout, rather than increasing the load, it is better to choose an appropriate density to improve resistance and wear resistance.

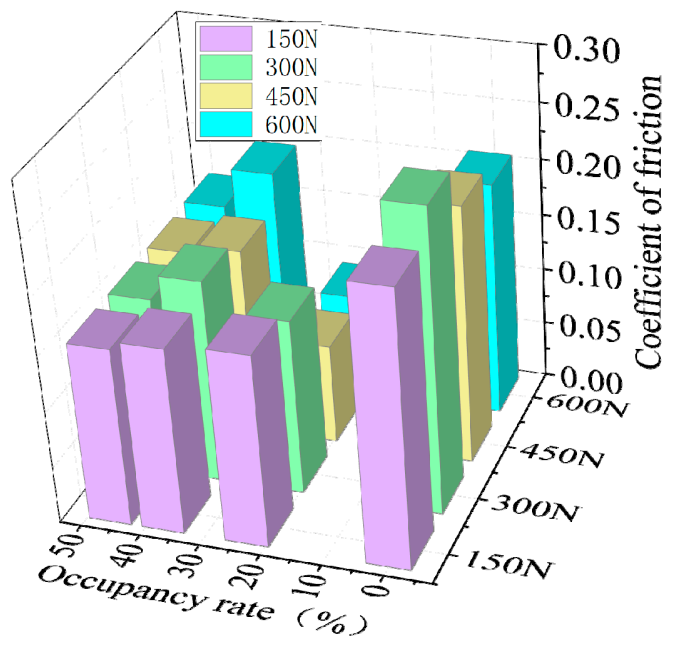

Figure 13. Effect of groove density on the coefficient of friction.

\section{Conclusions}

A growing number of researchers have dedicated their time to bionic texture drag reduction and wear-resistance, and they have made progress. In industrial production especially, the application of bionic surface micro texture tests has achieved considerable drag reduction, wear resistance, and lubrication effects while simultaneously saving resources, saving costs, and improving efficiency and working life. However, bionic texture belongs to micro technology, so further research is needed to realize large-scale applications.

(1) The most widely studied textures are those of the pit and groove types, of which the pit type has better wear resistance effects and the groove type has better drag reduction and lubrication effects.

(2) Here, the sample with a pit diameter of $10 \mu \mathrm{m}$ had the lowest coefficient of friction and abrasion amounts in the oil-free condition, and the pit with a depth of $3 \mu \mathrm{m}$ had the best wear resistance and wear rate; these findings can help to further improve friction and wear performance.

(3) Here, the effect of wear resistance and wear rate reduction was best when the groove width was $60 \mu \mathrm{m}$. Meanwhile, a reasonable groove pitch of $135 \mu \mathrm{m}$ was adopted, and this groove's density was $37 \%$.

(4) Micro-pits can store grinding debris under dry friction conditions and realize secondary lubrication under oil lubrication. When the oil is lubricated, a micro-groove can form a dynamic pressure effect in the convergence field, which can also realize secondary lubrication and reduce contact area.

(5) In order to analyze the dynamic pressure lubrication mechanism, one must set the boundary, simplify the Navier-Stokes equation according to the Couette flow, and obtain the relationship between the coefficient of friction and hydrodynamic parameters.

At present, the requirements of vehicle energy saving and emission reduction are becoming increasingly strict, and research in this field has become a hot spot. Due to the advancements in research on it and its gradually widening industrial applications, bionic textures will soon be used in space transportation system (they can be used to reduce the viscous resistance of wings and fuselage 
that is produced by the air friction speed), rail transit systems (they can be used to reduce the viscous resistance of end cars, trucks, pantographs and other important areas), automobiles, ship structures, and other objects that are widely used in high-speed movement. As such, bionic textures can and should be used to contribute to energy saving.

Author Contributions: Conceptualization, X.Y.; methodology, X.Y. and Q.H.; software, Q.H.; validation, Q.H., and X.Y.; formal analysis, Q.H.; investigation, Q.H.; data curation, Q.H.; writing-original draft preparation, Q.H.; writing-review and editing, X.Y.; supervision, J.X. and W.L.; project administration, X.Y.; contributions of authors, J.C., S.W., and D.D. All authors have read and agreed to the published version of the manuscript.

Funding: This work is supported by the National Natural Science Foundation of China (grant No. 51575234,51872122), the Postdoctoral Science Foundation of China (grant No. 2017M620286), the Key Research and Development Program of Shandong Province, China (grant No. 2018CXGC0809), the Agricultural Machinery Equipment Research and Development Innovation Plan of Shandong Province (grant No. 2018YF012), Experts from Taishan Scholars and Youth Innovation in Science \& Technology Support Plan of Shandong Prov-ince University.

Conflicts of Interest: The authors declare no conflict of interest.

\section{References}

1. Zhang, Q.; Chen, Z.H.; Wang, X.D. Bionics and Building Structure. Appl. Mech. Mater. 2011, 94, 450-455. [CrossRef]

2. Pal, J.W.; Yan, X.S.; Jen, F.L. Characteristics of water strider legs in hydrodynamic situations. Langmuir 2009, 25, 7006-7009.

3. Xu, Q.; Wan, Y.; Hu, T.S.; Liu, T.X.; Tao, D.; Niewiarowski, P.H.; Tian, Y.; Liu, Y.; Dai, L.; Yang, Y.; et al. Robust self-cleaning and micromanipulation capabilities of gecko spatulate and their bio-mimics. Nat. Commun. 2015, 6, 1-9. [CrossRef] [PubMed]

4. Bixler, G.D.; Bhushan, B. Fluid drag reduction with shark-skin riblet inspired micro structured surface. Adv. Funct. Mater. 2013, 23, 4507-4528. [CrossRef]

5. Liu, C.; Zhu, L.; Bu, W.; Liang, Y. Superhydrophobic surfaces: From nature to biomimetic through VOF simulation. Micron 2018, 107, 94-100. [CrossRef]

6. Guo, Z.; Yuan, C.; Liu, A.; Jiang, S. Study on tribological properties of novel biomimetic material for water-lubricated stern tube bearing. Wear 2017, 376, 911-919. [CrossRef]

7. Gropper, D.; Wang, L.; Harvey, T.J. Hydrodynamic lubrication of textured surfaces: A review of modeling techniques and key findings. Tribol. Int. 2016, 94, 509-529. [CrossRef]

8. Xing, Y.; Deng, J.; Feng, X.; Yu, S. Effect of laser surface texturing on Si3N4/TiC ceramic sliding against steel under dry friction. Mater. Des. 2013, 52, 234-245. [CrossRef]

9. Qin, Y.K.; Xiong, D.S.; Li, J.L. Tribological properties of laser surface textured and plasma electrolytic oxidation duplex-treated Ti6Al4V alloy deposited with MoS2 film. Surf. Coat. Technol. 2015, 269, $266-272$. [CrossRef]

10. Saeidi, F.; Meylan, B.; Hoffmann, P.; Wasmer, K. Effect of surface texturing on cast iron reciprocating against steel under starved lubrication conditions: A parametric study. Wear 2016, 348, 17-26. [CrossRef]

11. Fowell, M.; Olver, A.V.; Gosman, A.D.; Spikes, H.A.; Pegg, I. Entrainment and inlet suction: Two mechanisms of hydrodynamic lubrication in textured bearings. J. Tribol. 2007, 129, 336-347. [CrossRef]

12. Han, J.; Fang, L.; Sun, J.; Ge, S. Hydrodynamic lubrication of micro dimple textured surface using three-dimensional CFD. Tribol. Trans. 2010, 53, 860-870. [CrossRef]

13. Brizmer, V.; Kligerman, Y.; Etsion, I. A Laser Surface Textured Parallel Thrust Bearing. Tribol. Trans. 2003, 46, 397-403. [CrossRef]

14. Cheng, X.J.; Ru, S.F.; Sun, Y.W.; Cong, Q. Wear performance of bionic strip-shaped mud pump pistons. Proc. Inst. Mech. Eng. Part C J. Mech. Eng. Sci. 2017, 231, 4076-4084. [CrossRef]

15. Huang, W.; Wang, X. Biomimetic design of elastomer surface pattern for friction control under wet conditions. Bioinspiration Biomim. 2013, 8, 046001. [CrossRef]

16. Tan, A.H.; Wei, C.S. A novel textured design for hard disk tribology improvement. Tribol. Int. 2006, 39, 506-511. [CrossRef] 
17. Yu, H.Y.; Zhang, H.C.; Guo, Y.Y.; Tan, H.P.; Li, Y.; Xie, G.N. Thermodynamic analysis of shark skin texture surfaces for microchannel flow. Contin. Mech. Thermodyn. 2016, 28, 1361-1371. [CrossRef]

18. Ibatan, T.; Uddin, M.S.; Chowdhury, M.A.K. Recent development on surface texturing in enhancing tribological performance of bearing sliders. Surf. Coat. Technol. 2015, 272, 102-120. [CrossRef]

19. Ahmed, A.; Masjuki, H.H.; Varman, M.; Kalam, M.A.; Habibullah, M.; Al Mahmud, K.A.H. An overview of geometrical parameters of surface texturing for piston/cylinder assembly and mechanical seals. Meccanica 2016, 51, 9-23. [CrossRef]

20. Srinivas, S.; Babu, N.R. Penetration Ability of Abrasive Waterjets in Cutting of Aluminum-Silicon Carbide Particulate Metal Matrix Composites. Mach. Sci. Technol. 2012, 16, 337-354. [CrossRef]

21. Coblas, D.G.; Fatu, A.; Maoui, A.; Hajjam, M. Manufacturing textured surfaces: State of art and recent developments. Proc. Inst. Mech. Eng. Part J J. Eng. Tribol. 2015, 229, 3-29. [CrossRef]

22. Anonymous. Applied Physics; Researchers at Aachen University publish new data on applied physics. News Sci. 2008, 112, 65-93.

23. Wang, X.; Kato, K.; Adachi, K. The lubrication effect of micro-pits on parallel sliding faces of $\mathrm{SiC}$ in water. Tribol. Trans. 2002, 45, 294-301. [CrossRef]

24. Wang, X.; Adachi, K.; Otsuka, K.; Kato, K. Optimization of the surface texture for silicon carbide sliding in water. Appl. Surf. Sci. 2006, 253, 1282-1286. [CrossRef]

25. Yoo, J.; Yu, G.; Yi, J. Large-area multi-crystalline silicon solar cell fabrication using reactive ion etching (RIE). Sol. Energy Mater. Sol. Cells 2011, 95, 2-6. [CrossRef]

26. Balasubramaniam, R.; Krishnan, J.; Ramakrishnan, N. A study on the shape of the surface generated by abrasive jet machining. J. Mater. Process. Technol. 2002, 121, 102-106. [CrossRef]

27. Getu, H.; Ghobeity, A.; Spelt, J.K.; Papini, M. Abrasive jet micromachining of acrylic and polycarbonate polymers at oblique angles of attack. Wear 2008, 265, 888-901. [CrossRef]

28. Saragih, A.S.; Ko, T.J. Fabrication of passive glass micromixer with third-dimensional feature by employing SU8 mask on micro-abrasive jet machining. Int. J. Adv. Manuf. Technol. 2009, 42, 474-481. [CrossRef]

29. Voevodin, A.A.; Zabinski, J.S. Laser surface texturing for adaptive solid lubrication. Wear 2006, 261, 1285-1292. [CrossRef]

30. Andersson, P.; Koskinen, J.; Varjus, S.; Gerbig, Y.; Haefke, H.; Georgiou, S.; Zhmud, B.; Buss, W. Microlubricat ion effect by laser- textured steel surfaces. Wear 2007, 262, 369-379. [CrossRef]

31. Sanchez-Amaya, J.M.; Boukha, Z.; GonzGlez-Rovira, L.; Navas, J.; Martin-Calleja, J.; Botana, F.J. Laser texturization to improve absorption and weld penetration of aluminum alloys. J. Laser Appl. 2012, 24, 012002. [CrossRef]

32. Goya, K.; Itoh, T.; Seki, A.; Watanabe, K. Efficient deep-hole drilling by a femtosecond, $400 \mathrm{~nm}$ second harmonic Ti: Sapphire laser for a fiber optic in-line/pico-liter spectrometer. Sens. Actuators B Chem. 2015, 210, 685-691. [CrossRef]

33. Mistry, V.; James, S. Finite element analysis and simulation of liquid-assisted laser beam machining process. Int. J. Adv. Manuf. Technol. 2018, 94, 2325-2331. [CrossRef]

34. Ahmmed, K.M.T.; Grambow, C.; Kietzig, A. Fabrication of micro/nano structures on metals by femtosecond laser micromachining. Micro Mach. 2014, 5, 1219-1253. [CrossRef]

35. Pettersson, U.; Jacobson, S. Textured surfaces in sliding boundary lubricated contacts-mechanisms, possibilities and limitations. Tribol. Mater. Surf. Interfaces 2007, 1, 181-189. [CrossRef]

36. Koszela, W.; Dzierwa, A.; Galda, L.; Pawlus, P. Experimental investigation of oil pockets effect on abrasive wear resistance. ASME J. Tribol. 2012, 46, 145-153. [CrossRef]

37. Kim, B.; Chae, Y.H.; Choi, H.S. Effects of surface texturing on the frictional behavior of cast iron surfaces. Tribol. Int. 2014, 70, 128-135. [CrossRef]

38. Shen, X.H.; Tao, G.C. Tribological behaviors of two micro textured surfaces generated by vibrating milling under boundary lubricated sliding. Int. J. Adv. Manuf. Technol. 2015, 79, 1995-2002. [CrossRef]

39. Mourier, L.; Mazuyer, D.; Ninove, F.P.; Lubrecht, A.A. Lubrication mechanisms with laser-surface-textured surfaces in elasto hydrodynamic regime. Proc. Inst. Mech. Eng. Part J J. Eng. Tribol. 2010, 224, 697-711. [CrossRef]

40. Andriy, K.; Oyelayo, A. The effect of laser texturing of steel sur-faces and speed-load parameters on the transition of lubrication regime from boundary to hydrodynamic. Tribol. Trans. 2004, 47, 299-307. 
41. Ito, H.; Kaneda, K.; Yuhta, T.; Nishimura, I.; Yasuda, K.; Matsuno, T. Reduction of polyethylene wear by concave dimples on the frictional surface in artificial hip joints. J. Arthroplast. 2000, 15, 332-338. [CrossRef]

42. Kumari, R.; Scharnweber, T.; Pfleging, W.; Besser, H.; Majumdar, J.D. Laser surface textured titanium alloy (Ti-6Al-4V)-Part II-studies on bio-compatibility. Appl. Surf. Sci. 2015, 355, 104-111. [CrossRef]

43. Yu, A.B.; Niu, W.Y.; Hong, X.; He, Y.; Wu, M.; Chen, Q.; Ding, M. Influence of tribo-magnetization on wear debris trapping processes of textured dimples. Tribol. Int. 2018, 121, 84-93. [CrossRef]

44. Kawasegi, N.; Sugimori, H.; Morimoto, H.; Morita, N.; Hori, I. Development of cutting tools with microscale and nanoscale textures to improve frictional behavior. Precis. Eng. 2009, 33, 248-254. [CrossRef]

45. Noor, E.E.M.; Sing, H.A.; Chuan, Y.T. A review: Influence of nano particles reinforced on solder alloy. Solder. Surf. Mt. Technol. 2013, 25, 229-241. [CrossRef]

46. Lei, S.T.; Devarajan, S.; Chang, Z.H. A study of micro pool lubricated cutting tool in machining of mild steel. J. Mater. Process. Technol. 2009, 209, 1612-1620. [CrossRef]

47. Gao, X.; Chen, Q.; Teng, H.D. Primary resonance analysis of solid and liquid mixture vibration isolation system. J. Mech. Eng. 2012, 48, 90-95. [CrossRef]

48. Liu, N.; Wang, J.; Chen, B.; Yan, F. Tribo-chemical aspects of silicon nitride ceramic sliding against stainless steel under the lubrication of seawater. Tribol. Int. 2013, 61, 205-213. [CrossRef]

49. Jin, K.; Qiao, Z.; Zhu, S.; Cheng, J.; Yin, B.; Yang, J. Tribo-chemical properties of bronze-Cr-Ag alloy in seawater, $\mathrm{NaCl}$ solution and deionized water. Tribol. Int. 2016, 98, 1-9. [CrossRef]

50. Etsion, I.; Halperin, G.; Brizmer, V.; Kligerman, Y. Experimental investigation of laser surface textured parallel thrust bearings. Tribol. Lett. 2004, 17, 295-300. [CrossRef]

51. Borghi, A.; Gualtieri, E.; Marchetto, D.; Moretti, L.; Valeri, S. Tribological effects of surface texturing on nitriding steel for high-performance engine applications. Wear 2008, 265, 1046-1051. [CrossRef]

(C) 2020 by the authors. Licensee MDPI, Basel, Switzerland. This article is an open access article distributed under the terms and conditions of the Creative Commons Attribution (CC BY) license (http://creativecommons.org/licenses/by/4.0/). 